\title{
Suggested MRI criteria for surgical decompression in acute spinal cord injury. Preliminary observations
}

\author{
M Silberstein FRACR, ${ }^{1}$ D Brown FRACP, ${ }^{2}$ B M Tress FRACR, ${ }^{3}$ O Hennessey FRCR ${ }^{1}$ \\ ${ }^{1}$ Department of Radiology, ${ }^{2}$ Director of Spinal Injury Unit, Austin Hospital, Heidelberg, \\ Victoria 3084, Australia; ${ }^{3}$ Department of Radiology, Royal Melbourne Hospital, \\ Parkville, Victoria 3001, Australia.
}

The effect of spinal cord compression identified with magnetic resonance imaging (MRI), on neurological prognosis, was retrospectively evaluated in 36 patients with acute spinal cord injury. Of the 21 patients without cord compression, 16 had potentially reversible injury (normal spinal cord or cord oedema), all having functional recovery.

Of the 15 patients with cord compression, 3 had operative decompression. In the 12 patients who did not undergo surgery, the degree of recovery was directly related to the magnitude of spinal cord compression, only one of the patients with moderate or marked cord compression having useful motor function at follow up. In contrast, the 3 patients with surgical decompression had at least 2 grades of improvement, all having functional recovery. These findings raise the possibility that MRI may be used to identify a patient group who will benefit from surgical decompression. A numerical index is proposed to prospectively identify patients for surgical decompression, and further studies are underway to evaluate this.

Keywords: MRI; spine; spinal cord injury; quadriplegia; surgery.

\section{Introduction}

Spinal cord injury with subsequent quadriplegia or paraplegia is a major source of long term disability, yet effective treatment resulting in significant reduction in long term neurological deficit has proved frustrating. Although many might expect early surgical decompression of the spinal cord to be effective, the overwhelming majority of published work does not agree, ${ }^{1-3}$ and the only real advance, in over 400 years of research, has been the recent demonstration of improved neurological outcome following the administration of intravenous methylprednisolone within 8 hours of trauma, ${ }^{4}$ and the favourable results of a recently published small trial of a neural regenerative agent. ${ }^{5}$

Research in animal models has suggested that early cord decompression may be beneficial $^{2}$ but the inability to obtain accurate information regarding degree of cord compression, and specific pathological effects on the spinal cord prior to operation, has resulted in a failure to demonstrate significant benefit in the human.

We retrospectively evaluated magnetic resonance (MR) images of patients with spinal cord trauma to try and identify the effect of cord compression, as demonstrated on MR images, on neurological outcome and to establish imaging criteria for surgical decompression.

\section{Materials and methods}

Retrospective evaluation of 36 patients (26 males and 10 females) was performed. Ages ranged from 12 to 70 years with a mean age of 34 years. For inclusion in the study, the patient must have had a demonstrable acute neurological deficit following trauma to the spine with admission to the Austin Hospital Spinal Injuries Unit. All patients had MRI during their initial hospital admission, and all were classified according to injury type: 
transverse, central cord, and Brown Séquard; injury level: cervical or thoracic; and degree of functional deficit, according to the Frankel classification at time of MRI, and at follow up ${ }^{6}$ (Table I). Patients with injuries below the level of the conus medullaris, or with more than one clinical level of impairment, were excluded. The mechanism of injury was: motor vehicle accident (16), fall (8), diving (3), assault (3) and recreational sport (3). All patients had temporary spinal immobilisation, with 3 undergoing surgical decompression, between 6 hours and 12 days from injury. Follow up clinical assessments were obtained at 6 and 12 months following presentation on 31 patients and at 6 months only on 5 patients. The average time from injury to MR examination was 11 days (range 1 day to 42 days). Twenty-three patients had injuries to the cervical region and 13 to the thoracic region. MR imaging was performed with a 0.3 Tesla resistive MR unit (B 3000; Fonar; Melville NY) on 33 patients, and a 1.5 Tesla superconducting MR unit (Magnetom; Siemens; Germany) on 3 patients.

The MR images were analysed according to two major criteria: the appearances of the spinal cord, and the degree of cord compression, if any. Spinal cord appearances were grouped into cord transection, cord haematoma, cord contusion, cord oedema, and normal cord (Table II). Spinal cord compression was defined as non visualisation of an area of subarachnoid space in relation to the spinal cord. The degree of compression was graded according to the method of Takahashi ${ }^{7}$ into mild cord narrowing $(0-10 \%)$ moderate $(11-39 \%)$ and marked ( $40 \%$ or more).

\section{Results}

Of the 36 patients studied, 21 had no cord compression, including one patient with metallic artefact resulting in unsatisfactory images. Their results are presented in Table III. Patients with cord transection and haematoma failed to have any recovery while those with contusion improved one Frankel grade only. All 4 patients with cord oedema improved 3 Frankel grades to a
Table I Frankel classification

$\begin{array}{ll}\text { A } & \text { Complete motor and sensory loss } \\ \text { B } & \begin{array}{l}\text { Complete motor loss but some sensation } \\ \text { preserved }\end{array} \\ \text { C } & \begin{array}{l}\text { Some motor power preserved, but of no } \\ \text { functional use }\end{array} \\ \text { D } & \begin{array}{l}\text { Useful motor power, including walking } \\ \text { with or without aids }\end{array} \\ \text { E } & \text { Free of neurological symptoms }\end{array}$

Table II Criteria for spinal cord assessment on MRI

$\begin{array}{ll}\begin{array}{l}\text { Cord } \\ \text { transection }\end{array} & \begin{array}{l}\text { Partial or complete discontinuity } \\ \text { of the spinal cord on sagittal } \\ \text { images }\end{array} \\ \begin{array}{l}\text { Cord } \\ \text { haematoma }\end{array} & \begin{array}{l}\text { Focal area of high signal (bright) } \\ \text { on T1 weighted image or low } \\ \text { signal (dark) on T2 weighted } \\ \text { image }\end{array} \\ \text { Cord } & \begin{array}{l}\text { Either (a) heterogeneuos signal } \\ \text { from cord on T1 or T2 weight- } \\ \text { ing; (b) focal area(s) of high } \\ \text { signal on T1 image, surrounded } \\ \text { by much larger area of high } \\ \text { signal on T2 images; or (c) focal, } \\ \text { sharply defined area of high } \\ \text { signal on T2 image }\end{array} \\ & \begin{array}{l}\text { Diffuse, poorly defined area of } \\ \text { high signal on T2 image with } \\ \text { cord expansion, and normal } \\ \text { signal on T1 image }\end{array} \\ \text { Cord } & \end{array}$

Table III Results for patients without spinal cord compression

\begin{tabular}{lcl}
\hline Cord & $\begin{array}{l}\text { No of } \\
\text { patients }\end{array}$ & $\begin{array}{l}\text { Clinical change } \\
\text { (Frankel grades) }\end{array}$ \\
\hline Transection & 1 & AA \\
Haematoma & 1 & AA \\
Contusion & 2 & 1AB 1BC \\
Oedema & 4 & 4AD \\
Normal & 12 & 3AD 2BD 1CD \\
& & 2AE 1CE 3DE \\
MR artefact & 1 & AA
\end{tabular}

functional motor level. All 12 patients with normal cords improved to grade $\mathrm{D}$ or $\mathrm{E}$.

Fifteen patients had cord compression, 3 undergoing surgical decompression. The 
first of these was a patient with acute disc protrusion, moderate cord compression, cord oedema and Frankel grade $\mathrm{A}$, who had anterior discectomy and cervical fusion 8 hours after MRI and recovered to grade D (Fig 1). The second had asymptomatic Paget's disease of $\mathrm{T} 7$ and became a grade $\mathrm{C}$ incomplete paraplegic following a fall (Fig 2). He had marked cord compression with a normal cord, and following laminectomy 12 hours after MRI had complete recovery (grade $\mathrm{E}$ ). The third presented grade $\mathrm{A}$, paraplegic with normal cord and mild cord compression by extradural haematoma following a knife wound at T8. He improved to grade D following decompression 6 hours from injury. The results for the 12 patients who did not have surgical decompression are presented in Table IV. Two patients had cord swelling as a contributory factor to cord compression, with the remaining patients having cords of normal or reduced diameter but abnormal cord shape. The 2 patients with cord transection or haematoma had no recovery (grade A) while the 3 patients with contusion, although improving, did not have useful motor function at follow up. Of the 7 patients with cord oedema, 3 with mild compression had significant improvement to grade $\mathrm{D}$. The 4 patients with moderate or marked compression either had no improvement, or improved one grade only, with only one ( $C$ to $D)$ having useful motor function at follow up.

\section{Discussion}

The overwhelming majority of published work on early surgical decompression in acute spinal cord injury has shown no benefit in humans, and in some studies, neurological deterioration occurred following surgery. ${ }^{1,2}$ The selection of patients for decompression has, in the past, been based
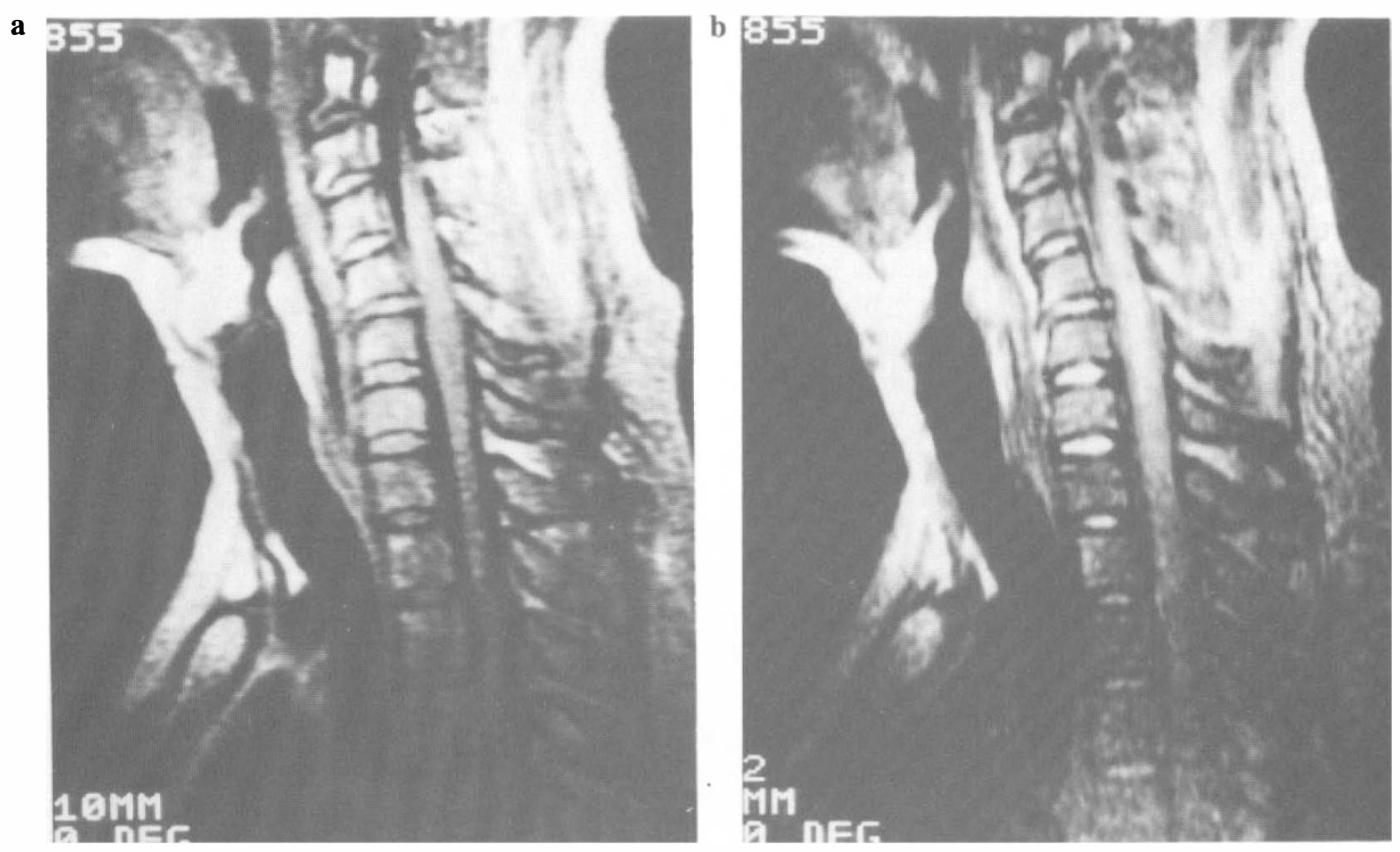

Figure 1 Mid sagittal magnetic resonance images obtained on acutely quadriplegic male, with almost complete recovery following anterior corpectomy and discectomy. (a) T1 weighted image showing focal spinal cord swelling opposite C5-C6 with focal disc protrusion reducing transverse cord diameter by $20 \%$. (b) T2 weighted image showing diffuse high signal intensity of spinal cord indicating oedema. Note disruption of anterior longitudinal ligament at C5-C6 and thin anterior epidural haematoma. 


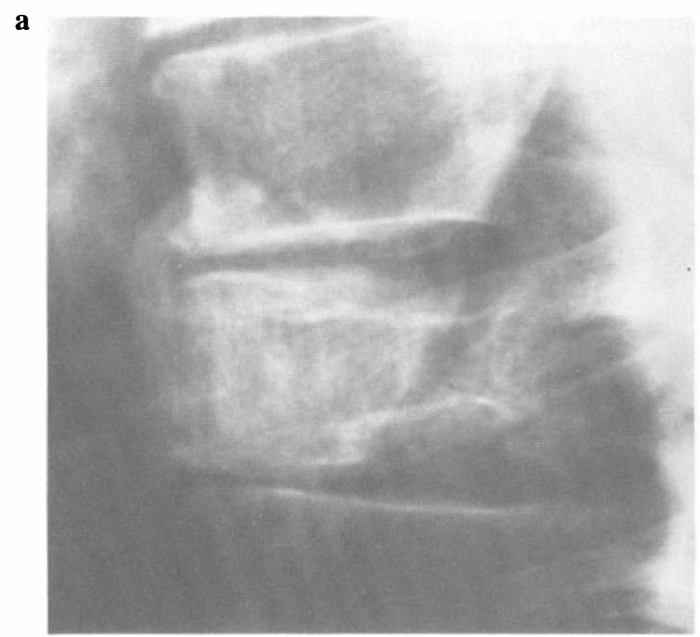

c

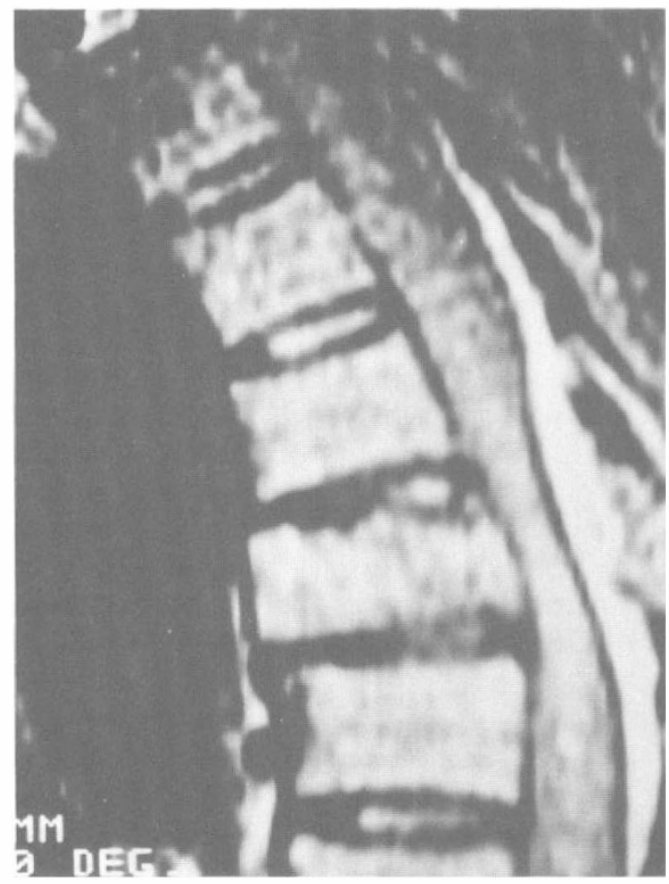

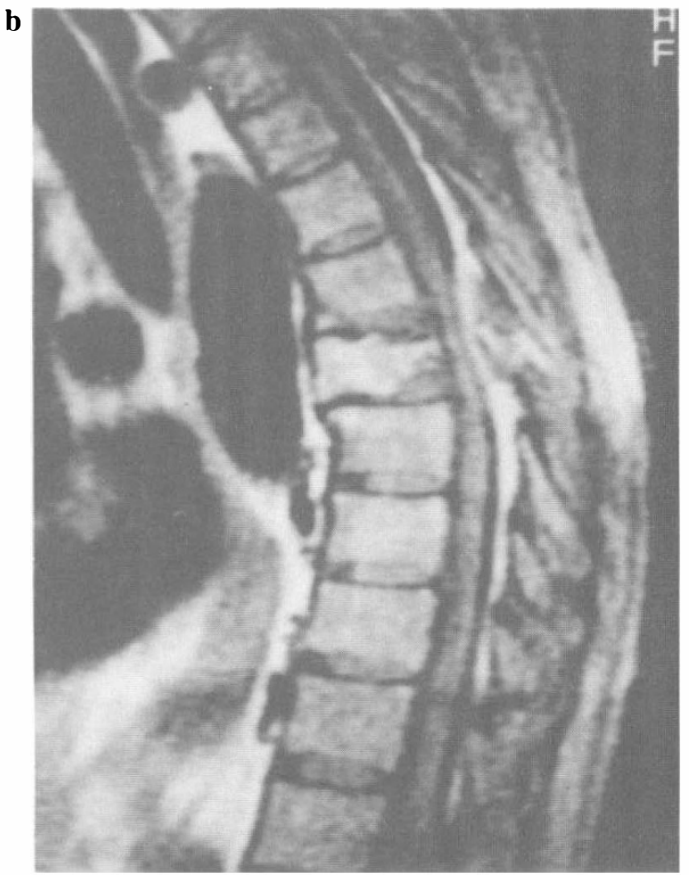

Figure 2 Lateral radiograph and sagittal magnetic resonance images obtained on an acutely paraplegic male, with complete recovery following laminectomy. (a) Lateral radiograph of the thoracic spine showing sagittal expansion and coarse trabecular pattern of $\mathrm{T} 7$ vertebral body consistent with Paget's disease. Note reduction in vertical diameter indicating compression fracture. (b) Mid sagittal T1 weighted MR image showing marked spinal cord compression, both anteriorly, by $\mathrm{T} 7$ vertebral body, and posteriorly by expanded neural arch. (c) T2 weighted image showing normal spinal cord signal intensity. on either clinical deterioration following hospital admission, ${ }^{3}$ or the degree of displacement at sites of fracture or dislocation. ${ }^{1}$ In no study was preoperative direct assessment of the spinal cord used, the technology only having recently become available with the advent of magnetic resonance imaging (MRI). Correlation of neuro- logical deficit with MRI appearances of the spinal cord has been demonstrated relatively recently ${ }^{8}$ but only two studies have related specific MRI findings at the time of injury to patterns of neurological outcome, one of 42 patients, ${ }^{9}$ the other of 21 patients. ${ }^{10}$ In a series of 78 patients, neurological deficit at presentation, and degree of 
Table IV Results for patients with spinal cord compression

\begin{tabular}{|c|c|c|c|c|c|}
\hline Cord & $\begin{array}{c}\text { No of } \\
\text { patients }\end{array}$ & Cause $^{\mathrm{a}}$ & Degree $^{b}$ & $\begin{array}{l}\text { Clinical } \\
\text { change }^{c}\end{array}$ & Index \\
\hline \multicolumn{6}{|c|}{ No decompression } \\
\hline Transection & 1 & Bone & Marked & AA & $\mathrm{N} / \mathrm{A}$ \\
\hline Haematoma & 1 & Bone & Marked & AA & $\mathrm{N} / \mathrm{A}$ \\
\hline \multirow[t]{3}{*}{ Contusion } & 3 & Bone/Haematoma & Moderate & $\mathrm{AC}$ & 7 \\
\hline & & Disc/Osteophyte & Moderate & AA & 7 \\
\hline & & Bone/Cord swelling & Mild & $\mathrm{AC}$ & 6 \\
\hline \multirow[t]{8}{*}{ Oedema } & 7 & Haematoma & Marked & AA & 9 \\
\hline & & Bone/Haematoma & Marked & $\mathrm{AB}$ & 9 \\
\hline & & Haematoma & Moderate & AA & 8 \\
\hline & & Bone & Moderate & $\mathrm{CD}$ & 6 \\
\hline & & Osteophyte & Mild & $\mathrm{AD}$ & 7 \\
\hline & & Haematoma/Cord & & & \\
\hline & & swelling & Mild & $\mathrm{AD}$ & 7 \\
\hline & & Haematoma/Osteophyte & Mild & $\mathrm{AD}$ & 7 \\
\hline \multicolumn{6}{|c|}{ Decompression } \\
\hline Oedema & 1 & Disc & Moderate & $\mathrm{AD}$ & 8 \\
\hline \multirow[t]{2}{*}{ Normal } & 2 & Bone & Marked & $\mathrm{CE}$ & 8 \\
\hline & & Haematoma & Mild & $\mathrm{AD}$ & 8 \\
\hline
\end{tabular}

a aetiology of cord compression.

${ }^{b}$ degree of compression (see text).

${ }^{c}$ clinical change - acute: follow up Frankel grade.

${ }^{\mathrm{d}}$ see text for discussion.

cord injury were significantly worse in patients with spinal cord compression identified using MRI. ${ }^{8}$

Is MRI a valid technique for the analysis of spinal cord compression? MR images yield anatomical information about the proximity of tissues, such as the spinal cord to the bony canal, but cannot provide true physiological information about pressures on these tissues. Therefore, the analysis of spinal cord compression using MRI is only an indirect guide to the true status of the spinal cord, but, lacking a method for noninvasive direct measurement of intraspinal pressures, MRI provides the closest approximation to the pathological situation.

In our study, although numbers are small, with only 3 patients having surgical decompression, $16(80 \%)$ of the patients without cord compression had useful motor function at follow up as opposed to 4 of $12(33 \%)$ with cord compression and no surgical decompression. If patients with MR evidence of cord haemorrhage or disruption (transection, haematoma and contusion) are excluded, then all 16 patients without cord compression improved to grade $\mathrm{D}$ or $\mathrm{E}$. Of the 12 patients with cord compression and no surgery, 5 had cord transection, haematoma or contusion, the latter group having the greatest recovery (to grade $\mathrm{C}$ ). The remaining 7 patients had cord compression with cord oedema. Of these, 3 had mild compression only, and recovered useful motor function (grade D). In contrast, 3 of the 4 patients with moderate or marked compression had complete motor paralysis at follow up (A or B), while the fourth improved one Frankel grade only (from $\mathrm{C}$ to D).

Whilst all 3 patients who had operative decompression improved 2 or more grades to $\mathrm{D}$ or better, direct comparison with the conservatively managed group is not straightforward, because the numbers are very small, and the injuries sustained by the patients who underwent surgery were quite heterogeneous. In an attempt to identify objective criteria for prospective spinal cord decompression, we devised an index based 
on clinical and MR findings. We allocated 3 scores to each patient with cord compression: a clinical score based on the Frankel classification $(\mathrm{E}=0 ; \mathrm{D}=1 ; \mathrm{C}=2 ; \mathrm{B}=3$; $\mathrm{A}=4) ;$ a compression score $($ mild $=1$; moderate $=2 ;$ marked $=3$ ); and a cord score (contusion $=1$; oedema $=2$; normal $=3$ ). The index is then derived:

$$
\begin{aligned}
\text { Index }= & \text { Clinical score }+ \text { Compression score } \\
& + \text { Cord score }
\end{aligned}
$$

The index for each of our patients is given in the far right column of Table IV. The 3 operated patients had indices of 8 or greater, as did the 3 patients with cord oedema who failed to have significant recovery. The remaining 4 patients with cord oedema and compression had indices of 7 or less and improved to grade D. The 3 patients with cord contusion also had indices of 7 or less. We applied our index to an additional patient in another institution with acute traumatic cervical disc protrusion, cord oedema, moderate compression and presentation grade A to give an index of 8 . This patient improved to D following anterior decompression. In previously published MR images of patients with clinical follow up, we identified 2 patients in whom we could grade the MRI appearances. ${ }^{10}$ Using our scoring system, both had indices of 8 or greater and improved following decompression. These small numbers do not allow any adequate statistical analysis, but suggest that selecting patients with indices of 8 or greater may offer improved chance of recovery if surgical decompression is performed.

This is far more optimistic than previous results. In a review of 267 patients with follow up after cervical spine injury, Bohlman concluded that although surgical intervention was not indicated for complete quadriplegia, anterior decompression was indicated in incomplete quadriplegia with myelographic evidence of anterior cord compression, on the basis of 6 out of 7 patients improving after decompressive surgery. ${ }^{1}$ In another study of 106 quadriplegic patients, 18 improved, of whom only 3 had decompression surgery. ${ }^{3}$

Whilst the presence or absence of cord compression influenced neurological outcome in this series, other factors also require consideration. In previously reported series, neurological outcome has been shown to be closely related to the MR appearance of the spinal cord. ${ }^{9,10}$ Patients with cord haematoma have the worst outcomes, those with contusion have little improvement, those with oedema frequently do well, and those with normal cords frequently recover. ${ }^{9}$ Patients with cord transection or haematoma in our series had no recovery, as expected. However, of the 5 patients with cord contusion 2 had no cord compression but improved only one Frankel grade, whereas 2 of the 3 patients with contusion and cord compression improved 2 Frankel grades (although no patient with cord contusion had useful motor function at follow up). What might explain these differences? Cord contusion is a heterogeneous group of conditions, and reflects a combination of haemorrhage, necrosis and oedema. Patients with predominantly haemorrhagic lesions will probably have less improvement than those in whom oedema predominates, regardless of the presence of cord compression. In general, our patients without cord compression had better outcomes than patients with cord compression, but this may primarily be due to the presence of 12 patients with normal cords in the group without cord compression, as opposed to no patients with normal cords in the group with cord compression but no surgery.

Certainly, the overall number of patients studied in this series was small, but there is evidence in recently published work by Flanders et $a l^{8}$ that cord compression following trauma is frequently associated with an abnormal cord, whereas normal cords frequently do not have cord compression. In their series of 78 patients examined with MRI, 30 had no cord compression, of whom at least 20 had normal cords. In contrast, although Flanders et al failed to state the total number of patients with normal cords in their compression group, and in some cases abnormal cords were categorised as displaying more than one abnormality, haemorrhage was found 5 times, and oedema 2.5 times, as frequently in those with cord 
compression as in those without compression. ${ }^{8}$ Cord compression is likely to be associated with a cord abnormality, and is the probable reason for the patient distribution in our series.

One other factor which should be considered is the time from injury to MR imaging. Of the 12 patients with cord compression and no surgery, 10 had spinal cords of normal or reduced diameter. Some patients develop cord atrophy and myelomalacia following injury resulting in reduced cord diameter, and these would not be expected to recover regardless of whether decompression was carried out. However all 10 patients in whom an index was calculated and surgery was not performed were examined with MRI within 14 days of injury. Spinal cord atrophy and myelomalacia are relatively late sequelae of spinal cord injury, and in the largest published series of patients with follow up MR imaging, were not seen earlier than 4 and 6 months from injury, respectively. ${ }^{11}$

MRI is a valuable technique in the management of patients with spinal cord injury as it yields important prognostic information by defining the nature of the injury to the cord.$^{9}$ It may, in the future, also be shown to directly influence patient treatment, as, by identifying the site and direction of cord compression and whether irreversible cord damage has occurred, MRI could guide the surgeon as to whether operation is indicated, and to the nature of the surgery, be it anterior corpectomy and discectomy, or laminectomy.

Because of the small numbers of patients in this series, any conclusion regarding the benefits of surgical decompression based on MRI findings cannot be reached, but we offer our methods to other centres, in the hope that, by pooling large numbers of patients, a statistically significant patient population can be accumulated to demonstrate whether our criteria can prospectively select patients with acute spinal trauma who will benefit from decompression surgery. We are currently establishing such a prospective trial at our institution.

\section{Acknowledgements}

We wish to acknowlegde the support of the Edith and Viola Reid Trust of The University of Melbourne, and the assistance of Dr David Thomas, and Mrs Rhonda Wykes in the preparation of the manuscript.

\section{References}

1 Bohlman HH (1976) Acute fractures and dislocations of the cervical spine: an analysis of three hundred hospitalized patients and review of the literature. J Bone Joint Surg 61(A): 119-142.

2 Janssen L, Hansebout RR (1989) Pathogenesis of spinal cord injury and newer treatments. A review. Spine 14: $23-32$.

3 Wilmot CB, Hall KM (1986) Evaluation of the acute management of tetraplegia: conservative versus surgical treatment. Paraplegia 24: 148-153.

4 Bracken MB, Shepard MJ, Collins WF, Holford TR, Young W, Baskin et al (1990) A randomized, controlled trial of methylprednisolone or naloxone in the treatment of acute spinal cord injury: results of the second National Acute Spinal Cord Injury Study. N Engl J Med 322: 1405-1411.

5 Geisler FH, Dorsey FC, Coleman WP (1990) Recovery of motor function after spinal cord injury - a randomized, placebo-controlled trial with GM-1 ganglioside. N Engl J Med 324: 1829-1838.

6 Frankel HL, Hancock DD, Hyslop G, Malzak J, Michaelis LS, Ungar GH et al (1969) The value of postural reduction in the initial management of closed injuries of the spine with paraplegia and tetraplegia. Paraplegia 7: 179-192.

7 Takahashi M, Sakomoto Y, Miyawaki M, Bussaka H (1987) Increased MR signal intensity secondary to chronic cervical cord compression. Neuroradiology 29: 550-556.

8 Flanders AE, Schaefer DM, Doan HT, Mishkin MM, Gonzales CF, Flanders AE et al (1977) Acute cervical spine trauma: correlation of MR imaging findings with degree of neurologic deficit. Radiology 177: 25-33.

9 Kulkarni MV, Bondurant FJ, Rose SL, Narayana PA (1988) 1.5 Tesla magnetic resonance imaging of acute spinal trauma. Radiographics 8: 1059-1082.

10 Mirvis SE, Geisler FH, Jelinek, Gellad F et al Acute cervical spine trauma: evaluation with $1.5 \mathrm{~T}$ MR imaging. Radiology 166: 807-816.

11 Kerslake RW, Jaspan T, Worthington BS (1991) Magnetic resonance imaging of spinal trauma. BJR 64: $386-402$. 